\title{
Development of a Power Generator System using Thermal Waste from a Car
}

\author{
Siti Halma Johari ${ }^{1}$, Norfariza Ab Wahab ${ }^{1}$, Nurliyana Abd. Mutalib ${ }^{1}$, \\ Suziana Ahmad ${ }^{1}$, Dayanasari Abdul Hadi ${ }^{1}$, Madiha Zahari ${ }^{1}$, Norlezah Hashim ${ }^{1}$, \\ Mazwin Mazlan ${ }^{2}$
}

${ }^{1}$ Faculty Teknologi Kejuruteraan Elektrik \& Elektronik, Universiti Teknikal Malaysia Melaka (UTeM), Hang Tuah Jaya, 76100 Durian Tunggal, Melaka, MALAYSIA

${ }^{2}$ Pusat Pengajian Kejuruteraan Sistem Elektrik,

Universiti Malaysia Perlis (UniMAP), Kampus Pauh Putra, 02600 Arau, Perlis, MALAYSIA

*Corresponding Author

DOI: https://doi.org/10.30880/ijie.2019.11.04.030

Received 8 August 2019; Accepted 26 August 2019; Available online 5 September 2019

\begin{abstract}
Wasted energy is created in our surroundings, including in a car's operating system. This paper presents the development of a power generator system using thermal waste from a car. Energy cannot be created or destroyed but it can be transferred or changed into other forms. Therefore, the objectives of this project are to study a working principles of Peltier and DC-DC boost converter, to propose a new power generator system by reusing the wasted thermal and generate a stable electric to supply car devices. A power generator system is created to reuse the thermal wasted. The system uses a thermoelectric generator to convert heat energy from a car to electrical energy when a difference in temperature occurs. The conversion process is achieved by using a Peltier module. With the small amount of voltage produced from the process, a DC-DC boost converter is used to boost the voltage from the converted voltage. The result of this study, the desired output voltage produce $5 \mathrm{~V}$ and it useful to supply back for car's devices or charge small electronic devices.
\end{abstract}

Keywords: Power generator, wasted thermal, DC-DC boost converter, Peltier module

\section{Introduction}

Energy cannot be created or destroyed but it can be transferred or changed into other different forms. Whenever energy is transferred, only a small amount will be changed into useful energy. Wasted heat energy is produced by a car from the processes involved in the conversion of fuel energy to mechanical or electrical energy [1]. In the car's combustion process, only about $30 \%$ of energy from the fuel will be used to move the car or run its accessories. The remaining $70 \%$ of the energy generated by the combustion of fuel in the car's engine cannot be converted into mechanical energy, but is instead dispersed to the environment as waste heat [2]. The Seebeck Effect is defined as a phenomenon in which a temperature difference between two dissimilar semiconductors produces a voltage between the two points [3]. The Peltier module has two sides, a cold side and a hot side, and includes an arrangement of thermoelectric module as shown in Fig. 1. 


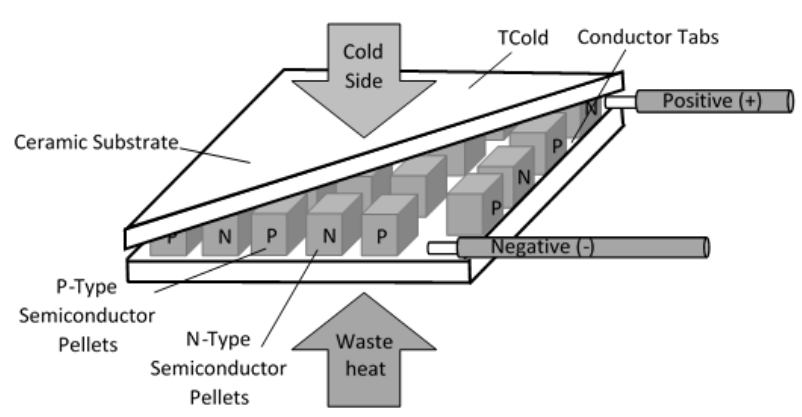

Fig. 1 - Peltier module.

A boost converter or step-up converter is used to amplify lower input voltage to higher output voltage. In the boost converter circuit, when the switch is closed, the load gets a voltage supply which charges through the current passing through the inductor, and when the switch is open, the load gets supply from the input stage and the inductor [4]. Fig. 2 shows an example of a boost converter circuit whilst Fig. 3 and Fig. 4 show the circuit condition when switch is closed and when the switch is open respectively.

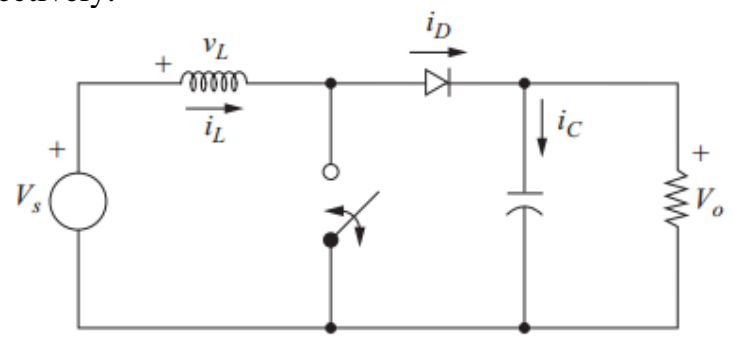

Fig. 2 - Boost converter circuit.

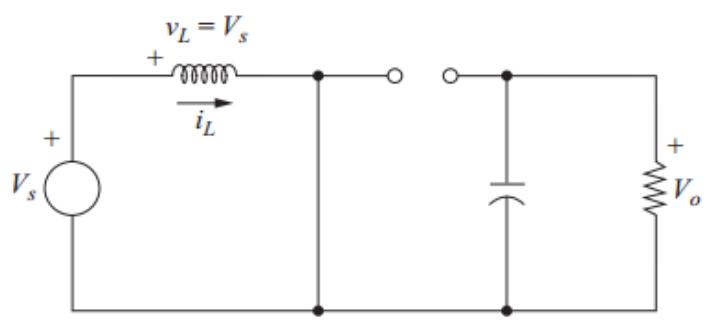

Fig. 3 - When the switch is closed.

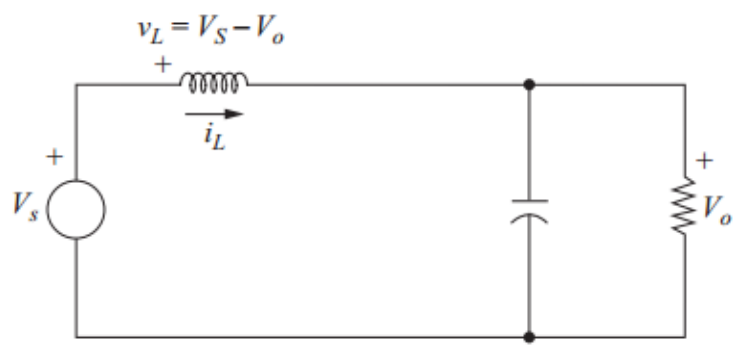

Fig. 4 - When the switch is open.

\section{Overview of The Design}

This project was conducted to study the Peltier working principle and the efficiency of energy conversion, to estimate the output voltage and current values of the related application, as well as to stabilise the power source using a DC-DC boost converter, design of the circuit with Peltier devices, DC-DC converter and the controller [5]. The aim of the power generator development is to convert waste heat energy sources to electrical sources that spread from car and supply electricity to a car's applications. The amount of heat that can be transferred to the thermoelectric materials are 
depending on the size of heat exchangers used to gain the heat from hot side and released it on the cold side [6]. The circuit needs to have stable and suitable output. By using only one Peltier, the input source supply to DC-DC boost converter is less than $0.6 \mathrm{~V}$ and it was affected the stability of output voltage to device. Therefore, the number of input sources, which is the number of Peltier, is increased to three and the system will become as shown as Fig. 5.

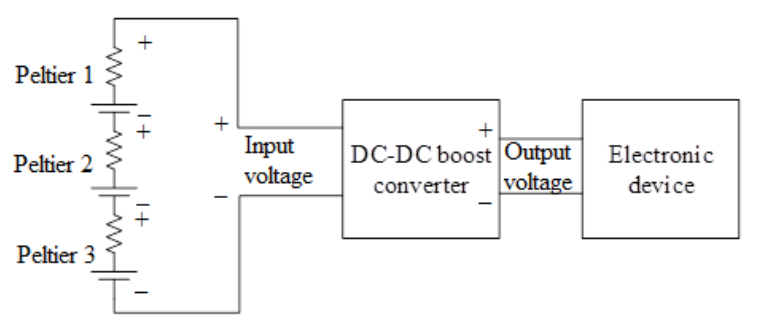

Fig. 5 - Overview of the system designed.

For the positioning in the car, the internal combustion engine is connected to the exhaust manifold. The hot side of the thermoelectric generator, which is the Peltier, gets heat from the exhaust manifold while the low temperature sources are on the cold side of the Peltier that contains the fan.

\section{Methodology}

Development of power generator system using thermal waste from car consist of hardware implementation. A Peltier absorbs heat energy that had spread from the car and the conversion process begins. The flowchart of this project is shown in Fig. 6 . The voltage is boosted by the boost converter to a suitable value and the desired voltage will be supplied to the application.

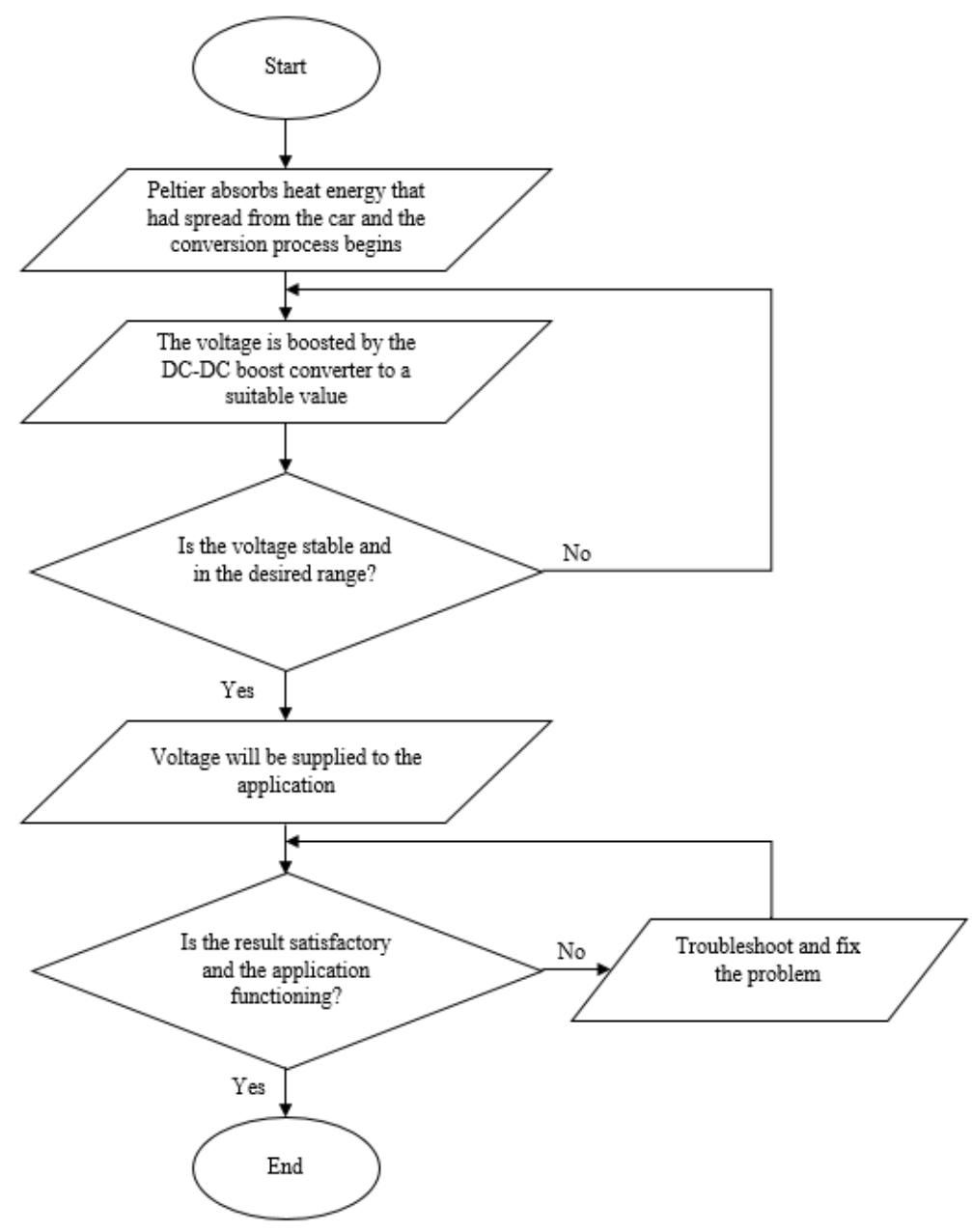

Fig .6 - Flowchart of the project. 
After testing several parts in a car, it was concluded that the heat shield for the exhaust manifold, as circled in Fig. 7, has the highest temperature. Heat flows out after combustion occurs in the engine, so this part has the highest temperature which is $169^{\circ} \mathrm{C}$ compared with its surroundings.

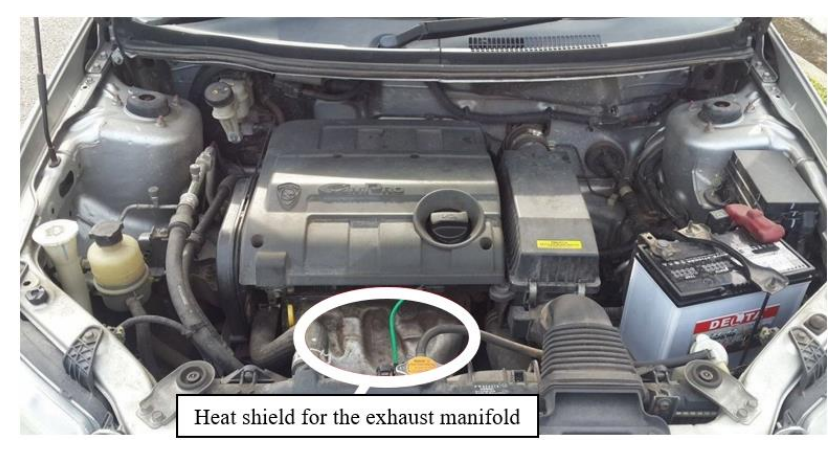

Fig. 7 - Heat source from a car.

Exhaust manifolds are generally simple cast iron or stainless steel units which collect engine exhaust gas from multiple cylinders and deliver it to the exhaust pipe [7]. It is protected by a heat shield and the hot side of the Peltier module will be in contact with the shield to receive the heat from the thermal wasted. The way of getting the temperature of the heat shield of the exhaust manifold is by using the infrared thermometer UT300A because of its mobility and how it can detect a high temperature range, from $-18{ }^{\circ} \mathrm{C}$ to $280{ }^{\circ} \mathrm{C}$. It is easily affected by surrounding temperatures if the distance is too far between the target and the infrared thermometer, so the distance needs to be set as short as possible to get accurate data [8]. Fig. 8 shows how temperature data is taken for the heat shield of an exhaust manifold using UT300A whilst Fig. 9 shows the complete product of three peltiers and DC-DC boost converter circuit box.

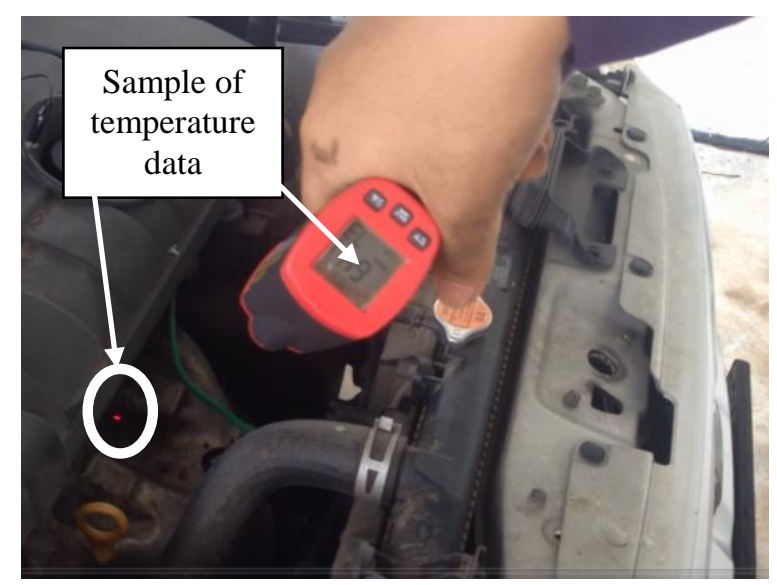

Fig. 8 - Sample of taking the temperature data using UT300A.

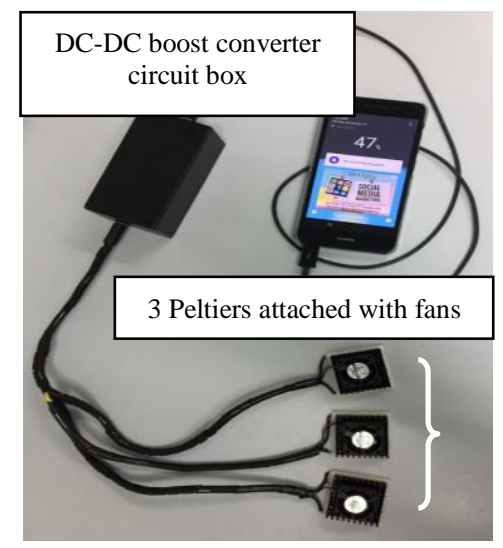

Fig. 9 - Three Peltiers and DC-DC boost converter circuit box. 


\section{Results and Discussion}

The temperature data of the exhaust manifold was taken every 30 seconds in a duration of 300 seconds. The process of taking the temperature data had to be done several times because the exhaust manifold needs at least four hours to cool down to the surrounding temperatures. After the temperature data was taken for several times, the most similar of the three data was selected and tabulated in Table 1.

Table 1 - Temperature data from the heat shield of the exhaust manifold.

\begin{tabular}{ccccc}
\hline Times (s) & $\begin{array}{c}\text { Temperature1 } \\
\left({ }^{\mathbf{C}} \mathbf{C}\right)\end{array}$ & $\begin{array}{c}\text { Temperature2 } \\
\left({ }^{\mathbf{}} \mathbf{C}\right)\end{array}$ & $\begin{array}{c}\text { Temperature3 } \\
\left({ }^{\circ} \mathbf{C}\right)\end{array}$ & $\begin{array}{c}\text { Average Temperature } \\
\left({ }^{\circ} \mathbf{C}\right)\end{array}$ \\
\hline 0 & 32.70 & 33.10 & 32.90 & 32.90 \\
30 & 46.10 & 44.70 & 49.30 & 46.70 \\
60 & 72.20 & 65.80 & 68.40 & 68.80 \\
90 & 82.90 & 83.40 & 84.60 & 83.63 \\
120 & 98.80 & 96.60 & 97.90 & 97.77 \\
50 & 115.60 & 112.20 & 115.80 & 114.53 \\
180 & 121.00 & 121.60 & 123.60 & 122.07 \\
210 & 133.60 & 134.20 & 134.90 & 134.23 \\
240 & 147.20 & 143 & 142.90 & 144.37 \\
270 & 157 & 155.10 & 153.40 & 155.17 \\
300 & 169 & 167.8 & 168.2 & 168.33 \\
\hline
\end{tabular}

The average temperatures were calculated from Table 1 for every time period and the data plotted in a graph as shown in Fig. 10. From the graph show that the temperature gradually increased by the time.

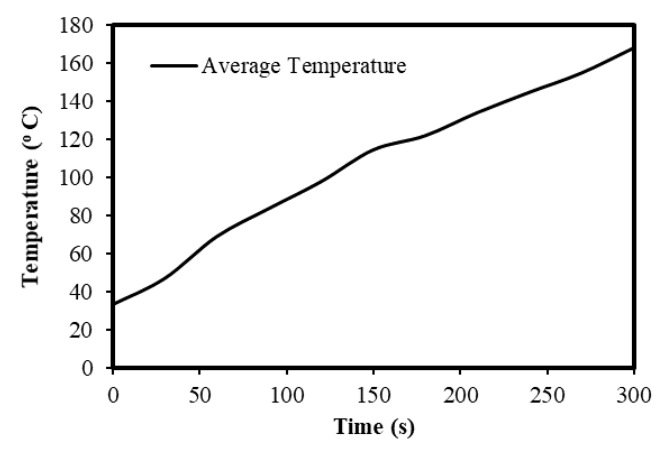

Fig. 10 - Average temperatures $\left({ }^{\circ} \mathrm{C}\right)$ of the exhaust Manifold.

The construction circuit is tested on exhaust manifold for several times, the input voltages against time was plotted as per Fig. 11 whilst Input voltage (V) against Temperature $\left({ }^{\circ} \mathrm{C}\right)$ is shown in the graph in Fig. 12.

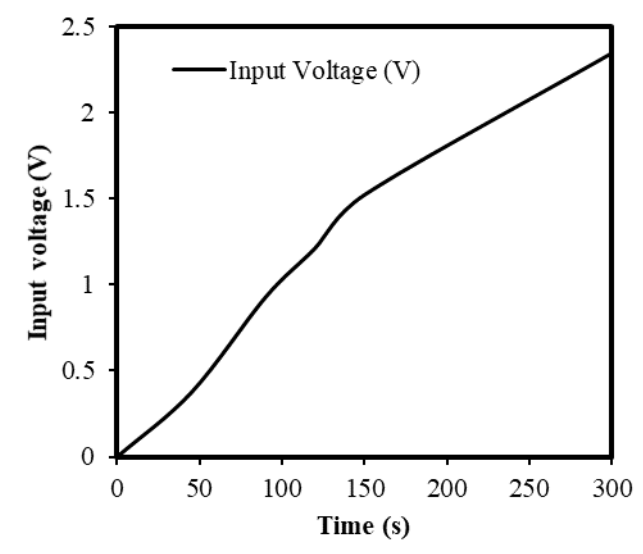

Fig. 11 - Input Voltage (V) against Time (s). 


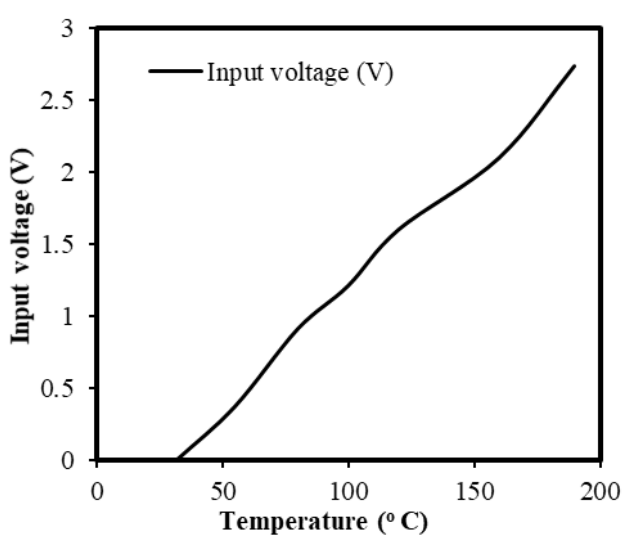

Fig. 12 - Input Voltage (V) against Temperature $\left({ }^{\circ} \mathrm{C}\right)$.

From the graphs, it can be seen that the input voltage increases with time or temperature [9]. With the time increasing, temperature of the exhaust manifold increases, thus the voltage input and current sources will increase due to the heat being received getting stronger. Input Current $(\mathrm{mA})$ against Time (s) is as shown in Fig. 13.

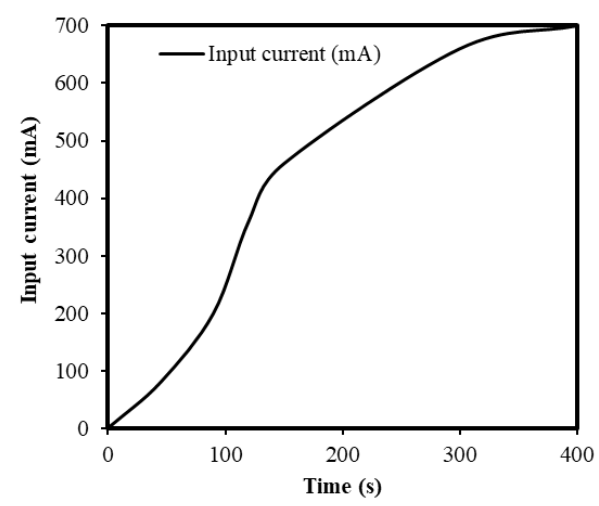

Fig. 13 - Input Current (mA) against Time (s).

Input Current $(\mathrm{mA})$ against Temperature $\left({ }^{\circ} \mathrm{C}\right)$ is plotted as per Fig. 14. The input currents increase based on time or temperature. The wasted heat that spreads from the exhaust manifold is converted to input voltage and current by Peltiers.

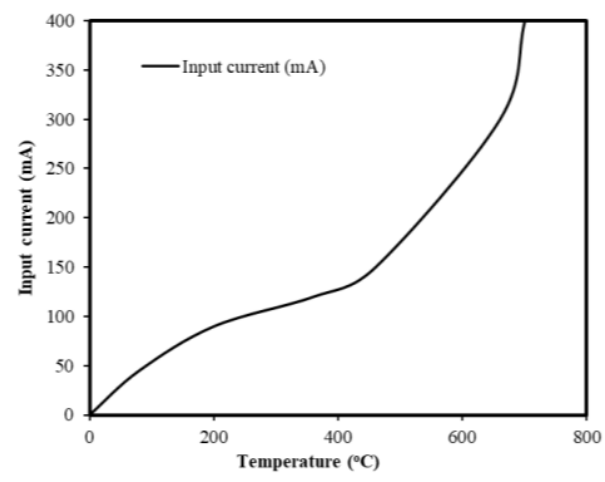

Fig. 14 - Input Current (mA) against Temperature $\left({ }^{\circ} \mathrm{C}\right)$.

The input sources will be boosted by the boost converter and supplied to output. After several tests have been carried out for the boost converter, the boost converter needs at least $0.6 \mathrm{~V}$ to be activated and give output $5 \mathrm{~V}$. Fig. 15 shown the output voltage of the boost converter against time. 


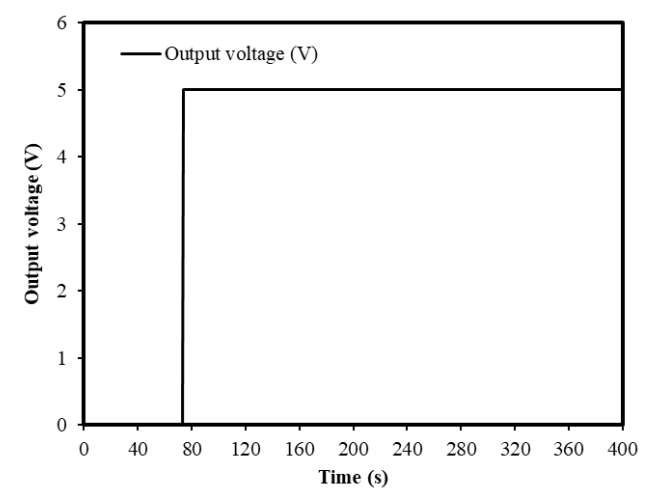

Fig. 15 - Output Voltage (V) against Time (s).

The voltage is equal to zero before the optimum conditions are achieved and increases significantly when the boost converter is activated. It proves that at certain conditions, ie at $74 \mathrm{~s}$, with a temperature of $70{ }^{\circ} \mathrm{C}$ and input voltage having reached $0.6 \mathrm{~V}$, the boost converter is activated and the output voltage rises dramatically to $5 \mathrm{~V}$. Then, Output Current (mA) against Time (s) is plotted as per Fig. 16.

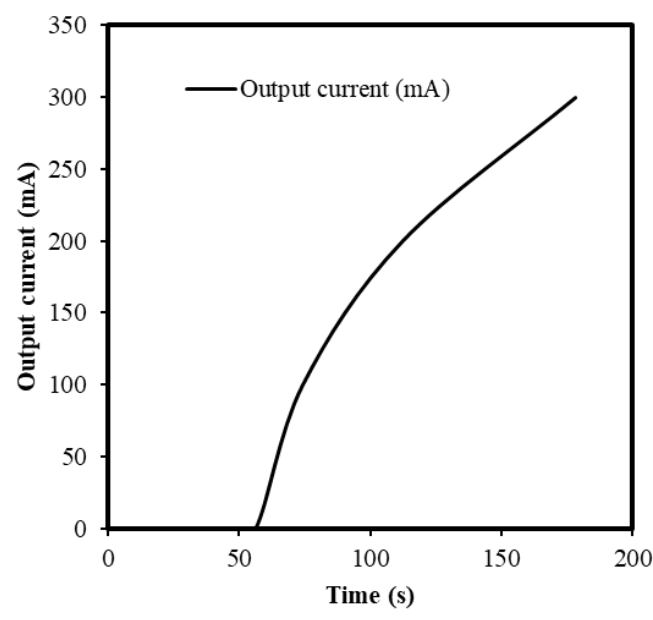

Fig. 16 - Output Current (mA) against Time (s).

A combination for the graph has been plotted as Time against Temperature and Voltage. Therefore, comparison is made between the data. The graph of the overall of the data analysis is as shown in Fig. 17.

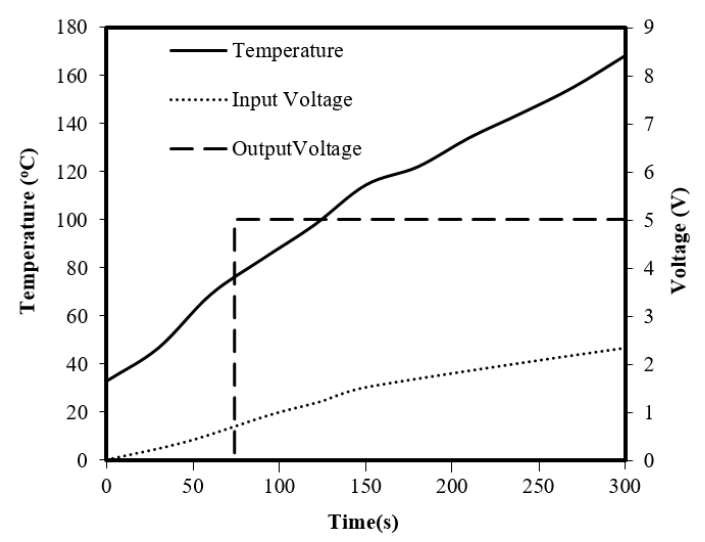

Fig. 17 Overall data analysis.

The graph in Fig. 17 shows the overall data for the power generator system. The line shows that the temperature of the exhaust manifold increases with time. The dotted line shows that the input voltages increase with time. Both the dotted and dash lines are increasing at difference rates based on time. For the output voltage, shown by the dash line, 
the boost converter needs at least $0.6 \mathrm{~V}$ of input voltage to activate, so at the early stage when the boost converter is not activated, the output voltages remain at $0 \mathrm{~V}$. When input voltage of $0.6 \mathrm{~V}$ is reached, then the output voltage will significantly increase from $0 \mathrm{~V}$ to $5 \mathrm{~V}$ and maintain the same voltage after the increased period.

\section{Summary}

Place the temperature difference between the two sides plays an important role as the rate of voltages produced by the Peltier. The Peltier produces voltages based on the temperature of the exhaust manifold and the bigger temperature differences will cause the voltage values to be higher. The objectives for power generator development have been archived for the study of the working principle of Peltier and DC-DC boost converter, implementation of a new power generator system by reusing wasted thermal energy from a car and obtaining a high efficiency for the conversion process and a stable output electric source.

\section{Acknowledgement}

This work was partially supported by Universiti Teknikal Malaysia Melaka (UTeM) and the Malaysia Ministry of Education, Higher Education for the financial funding under Grant No. PJP/2018/FTK(1B)/S01580.

\section{References}

[1] Tak, M, Technology, C., and Setia, M. Converting waste heat from automobiles to electrical energy feasibilty and potential of thermoelectric conversion," in IEEE 7th International Power Electronics and Motion Control Conference, (2012), pp. 2095-2098.

[2] Han, W., and Motor, G. Thermoelectric waste heat recovery for automotive. in International Microsystems, Packaging Assembly and Circuits Technology Conference, (2014), pp. 57-60.

[3] Velmre, E. Thomas Johann Seebeck and his contribution to the modern science and technology. BEC $2010-2010$ 12th Bienn. Balt. Electron. Conf. Proc. 12th Bienn. Balt. Electron. Conf., (2010), pp. 17-24.

[4] Roshan, Y. M., and Moallem, M. Control of a boost converter for resistive input behavior in the continuous conduction model. IECON Proc. (Industrial Electron. Conf., (2012), pp. 310-315.

[5] Johari, S. H. et al. Performance analysis of portable power generator by using TEG module," in Proceeding of Mechanical Engineering Research Day, (2016), pp. 79-80.

[6] Hisham, A. A. B., Saad, S. A., Ahmad, M. R. R., Rahim, R. A., Idris, N. H., and Ishak, M. H. I. Review of safety evaluation of thermal wearable power harvesting device. Int. J. Integr. Eng., Volume 9, No. 4 (2017), pp. 76-84.

[7] Manigandan, A., Raghunandhan, S., Sanjay, R., Kumar, S. S., and Sitarth, R. Thermoelectric cooling from exhaust gas manifold. Int. J. Innov. Res. Sci. Eng. Technol., Volume 5, No. 8, (2016), pp. 272-277.

[8] Nunak, T., Nunak, N., Tipsuwanporn, V., and Suesut, T. Surrounding effects on temperature and emissivity measurement of equipment in electrical distribution system. Lect. Notes Eng. Comput. Sci., Volume 2219, No. 2, (2015).

[9] Babu, S. R., and Vedasagar. D. Thermoelectric power generation using Bismuth-Tin module. International Journal for Research in Electronics \& Electrical Engineering, Volume 2, No. 5, (2016), pp. 7-13. 